\title{
Assessment of Grape Yield and Composition Using Reflectance- Based Indices in Rainfed Vineyards
}

\author{
Cristina González-Flor, Lydia Serrano,* Gil Gorchs, and Josep M. Pons
}

\begin{abstract}
Spectral vegetation indices such as the normalized difference vegetation index (NDVI) have proved to be useful in estimating berry yield and composition in irrigated vineyards that usually experience mild to moderate water deficits. However, their performance is not clear under rainfed conditions. This study explores the relationships between NDVI and berry yield and composition in rainfed vineyards experiencing mild to moderate water stress with respect to the timing of water deficits. The study was conducted on grape (Vitis vinifera $\mathrm{L}$. 'Chardonnay'). Biophysical variables such as predawn water potential $\left(\Psi_{\mathrm{p}}\right)$, canopy minus air temperature difference $\left(\Delta T_{\mathrm{m}}\right)$, fractional intercepted photosynthetic active radiation (fIPAR) and canopy reflectance measurements were acquired at veraison and were related to berry yield, total soluble solids (TSS), titratable acidity (TA), and maturity index (IMAD) at harvest. In our study, while NDVI provided consistent estimates of TSS $\left(r^{2}=0.81\right)$ and IMAD $\left(r^{2}=\right.$ 0.89 ) when water deficit conditions had a larger incidence before veraison, the water index (WI)-a reflectance-based index of water status-was related to TA $\left(r^{2}=0.62\right)$ and IMAD $\left(r^{2}=0.67\right)$ under post-veraison water deficits. Since early and late water deficits (i.e., before and after veraison) have a differential impact on the determinants of vine photosynthetic activity (i.e., leaf area and stomatal conductance), the capability of NDVI to estimate berry yield and composition might be subject to the extent and timing of water deficits in these rain-fed vineyards.
\end{abstract}

Vitis vinifera L. is a widespread crop in regions with a Mediterranean-type climate. Particularly in the Mediterranean arc, where vines for wine production are typically grown without irrigation support, water deficits are known to exert large constraints on grape production (Medrano et al., 2003). Moreover, vine water status has been recognized as the factor that most comprehensively determines berry ripening and composition (Choné et al., 2001; Deloire et al., 2004; Koundouras et al., 2006).

The effect of water deficits on grapevine production depends mainly on the stage of canopy growth and berry development when the water deficit occurs. Pre-veraison water deficits (i.e., during early canopy development and early berry formation) can reduce shoot growth and can affect berry cell division, leading to smaller berries and, potentially, reduced yield (Matthews et al., 1987; Koundouras et al., 2006; Ojeda et al., 2001; Van Leeuwen et al., 2009) whereas post-veraison water deficits (i.e., from veraison to harvest) affect berry cell expansion, causing a reduction in yield as a result of decreased berry weight (Ojeda et al., 2001; Chaves et al., 2010). While progressive water deficits reduce yield regardless

Departament d'Enginyeria Agroalimentària i Biotecnologia, Universitat Politècnica de Catalunya, c/Esteve Terradas, 8, 08860 Castelldefels (Barcelona). Spain. Received 31 Dec. 2013. ${ }^{*}$ Corresponding author (lydia. serrano@upc.edu).

Published in Agron. J. 106:1309-1316 (2014)

doi:10.2134/agronj13.0422

Copyright ( $\odot 2014$ by the American Society of Agronomy, 5585 Guilford Road, Madison, WI 53711. All rights reserved. No part of this periodical may be reproduced or transmitted in any form or by any means, electronic or mechanical, including photocopying, recording, or any information storage and retrieval system, without permission in writing from the publisher. of the differences in canopy and berry developmental responses to the timing of water stress, the response to water deficits in terms of berry composition is more complex. Indeed, previous studies have reported positive and negative effects, as well as no effects at all, on berry sugar concentration and titratable acidity in response to water deficits (Matthews and Anderson, 1988; Koundouras et al., 2006, Van Leeuwen et al., 2009). These different responses have been attributed to differences in vigor and, therefore, sourcesink equilibrium, as well as to different berry developmental and metabolism responses to the timing and intensity of water stress imposition (Koundouras et al., 1999; Jackson and Lombard, 1993; Chaves et al., 2010; Van Leeuwen et al., 2009).

Water deficits influence berry composition through their effects on berry size and on photosynthetic activity. Moreover, photosynthetic activity (i.e., $\mathrm{C}$ assimilation) and source-sink ratios have been recognized as playing an important role in the seasonal variation of water and $\mathrm{C}$ transport, and accumulation in the grape berry, thereby influencing sugar levels and acid balance (Coombe, 1989). In addition, water deficits are known to have an indirect and always positive effect on the concentration of berry compounds due to berry size reduction (Bravdo et al., 1985; Chaves et al., 2010). Therefore, since vine water status largely determines $C$ acquisition and water loss (Patakas et al., 2005) and regulates the source-sink relationships (Van Leeuwen et al., 2009), indicators of grapevine water status might be a valuable tool for characterizing

Abbreviations: $\Psi_{\mathrm{p}}$, predawn water potential; fIPAR, fractional intercepted photosynthetic active radiation; IMAD, maturity index; NDVI, normalized diference vegetation index; PCD, plant cell density; TA, titratable acidity; $\Delta \mathrm{T}_{\mathrm{m}}$, leaf to air temperature difference; TSS, total soluble solids; WI, water index. 
the effects of water stress on berry composition (Cifré et al., 2005; Chaves et al., 2010; Serrano et al., 2012).

Nowadays, remote-sensing technologies are being widely used in precision viticulture because they provide rapid, nondestructive, and cost-effective spatial characterization of vine size and vigor, which are potential indicators of fruit yield and quality (Hall et al., 2002; Lamb, 2000). However, while remote estimates of vine vigor such as plant cell density (PCD) or NDVI have provided consistent estimates of berry yield and composition in irrigated vineyards (Johnson et al., 2001; Lamb et al., 2008; Hall et al., 2011), changes in NDVI failed to predict variation in grape quality attributes in rainfed vineyards experiencing water stress (Acevedo-Opazo et al., 2008; Serrano et al., 2012). Thus, the question arises as to whether spectral indices related to photosynthetic biomass might be able to capture the complex effects of vine water status on photosynthetic functioning and, thereby, on berry composition. Remote-sensing indicators of photosynthetic biomass, such as NDVI or PCD, might be able to track vine photosynthetic functioning when changes in leaf area largely determine variation in $\mathrm{C}$ acquisition. This is likely to occur when vines experience early water deficits (i.e., before veraison) because water stress during the vegetative growth period has a large impact on vine vigor (i.e., leaf area) (Matthews et al., 1987). However, NDVI might not properly characterize variation in photosynthetic functioning when water deficits develop late in the season (i.e., post-veraison) because ample water availability before veraison might result in small differences in vine vigor but subsequent water deficits are likely to decrease stomatal conductance (Flexas et al., 2002) and, thus, photosynthesis. Therefore, whether the effects of water deficits on $\mathrm{C}$ assimilation are predominantly due to reduced canopy size (leaf area) or to a decline in photosynthetic rate (i.e., stomatal closure) might explain to some extent the differences in the capability of NDVI to estimate berry yield and composition that have been found in previous studies.

Remote-sensing indices of vine water status might provide valuable information for characterizing berry yield and composition in vineyards experiencing water deficits. Several remote-sensing indicators have been proposed to estimate vine water status in vineyards, such as passive chlorophyll fluorescence (Flexas et al., 2000; Dobrowski et al., 2005), infrared thermometry (Grant et al., 2007; Jones et al., 2002), and hyperspectral reflectance indices (RodríguezPérez et al., 2007; Serrano et al., 2010). Numerous studies have focused on the remote detection of vine water status using reflectance indices, but fewer have assessed the potential to estimate yield and fruit quality. Sepulcre-Cantó et al. (2007) have shown the capability of thermal imagery to determine water stress effects on yield and fruit quality in olive (Olea spp.) orchards. In addition, recent studies have shown the capability of the reflectance-based water index (WI) (Peñuelas et al., 1993) to characterize berry composition in vineyards experiencing moderate to severe water stress (Serrano et al., 2012). The present study assesses the capability of the spectral indices NDVI and WI to estimate berry yield and composition over 2 yr characterized by mild to moderate water deficits occurring at different times in the growth cycle (i.e., pre and post-veraison).

\section{MATERIALS AND METHODS}

\section{Study Site}

The study was performed in seven commercial vineyards of $V$. vinifera L. 'Chardonnay' located in the Alt Penedès and Anoia counties (Catalonia, Spain, $1^{\circ} 48^{\prime} 22^{\prime \prime} \mathrm{W} ; 41^{\circ} 28^{\prime} 54^{\prime \prime} \mathrm{N}$ ) over 2 yr
(2009 and 2011). The region has a Mediterranean climate with an average annual temperature of $15^{\circ} \mathrm{C}$ and mean annual rainfall of $550 \mathrm{~mm}$. Soil texture is loam and loamy-silt with medium to high carbonate content (ranging from 13-42\%) and $\mathrm{pH}$ is around 8.5. Soil depth ranges from 0.8 to $2.0 \mathrm{~m}$ among vineyards. Vines were planted between 1990 and 2001 at variable density, ranging from 2083 to 3703 stock ha ${ }^{-1}$ and the training system was Double Royat. Vines were grown under rainfed conditions and berries were harvested for "cava" (sparkling wine) production.

In each vineyard, three individual vines with contrasting vigor were chosen to be measured at the veraison stage, when the vines attained full canopy expansion. This phenological stage was chosen on the basis of previous studies aimed at forecasting berry yield and composition from remote-sensing data (Lamb et al., 2008). Veraison (i.e., when field data collection took place) occurred around the third week of July in 2009, whereas in 2011 it took place about 10 $\mathrm{d}$ earlier. Subsequently, at harvest, yield and quality attributes were determined for the same vines. Weather data were obtained at a nearby weather station located in Els Hostalets de Pierola (1 $48^{\prime} 31^{\prime \prime}$ $\left.\mathrm{W} ; 41^{\circ} 31^{\prime} 59^{\prime \prime} \mathrm{N}\right)$. The average temperature over the growth cycle (i.e., from November-October) is $15.0^{\circ} \mathrm{C}$, ranging from 13.7 to $15.8^{\circ} \mathrm{C}$, and cumulative precipitation is $499 \mathrm{~mm}$, ranging from 266 to $752 \mathrm{~mm}$. The weather water balance-the difference between precipitation $(P)$ and reference evapotranspiration $\left(\mathrm{ET}_{0}\right)$-was calculated using the Penman-Monteith equation, considering the following phenological stages: (i) dormancy, from 1 November to budburst; (ii) vegetative growth, from budburst to anthesis; (iii) berry growth, from anthesis to veraison; (iv) ripening, from veraison to harvest; and (v) post-harvest, from harvest to 31 October.

\section{Vine Water Status and Vigor}

Predawn water potential $\left(\Psi_{\mathrm{p}}\right)$, canopy to air temperature difference at midday $\left(\Delta T_{\mathrm{m}}\right)$ and fractional fIPAR measurements were performed at the veraison stage (i.e., around 15-31 July), except in 2011, when data were collected shortly before veraison (first week of July). Predawn water potential was determined using a pressure chamber (Soilmoisture 3005, Soil Moisture Corp., Santa Barbara, CA). Measurements took place before sunrise on a single mature, external leaf per vine. Canopy temperature was measured on both the sun-exposed and shaded side of the vine at midday using a handheld infrared thermometer (ST Pro Plus, Raytek Corp., Santa Cruz, CA) placed approximately $20 \mathrm{~cm}$ from the canopy at an angle of $\sim 60^{\circ}$. Values of $\Delta T_{\mathrm{m}}$ were derived using air temperatures acquired in the field concurrently to canopy temperature measurements. The fIPAR measurements were performed using a handheld ceptometer (Accupar, Decagon Devices Inc., Pullman, WA) as described in Serrano et al. (2012).

\section{Spectral Measurements}

Spectral data were acquired using a narrow-band spectroradiometer (UNISPEC, PP Systems Ltd., Haverhill MA) at midday (solar noon) on cloudless days. The detector samples 256 bands at roughly even intervals (average band-to-band spacing $3.3 \mathrm{~nm}$ ) within a 400 to $1100 \mathrm{~nm}$ effective spectral range. Irradiance was measured using a cosine-corrected detector lens (UNI-685 PP Systems Ltd., Haverhill MA) mounted on a tripod boom located above the vines and oriented to the sky. Canopy radiance was measured using a $12^{\circ}$ field-of-view foreoptic (UNI710, PP Systems Ltd., Haverhill MA) connected to the spectroradiometer via a 
Table I. Average temperature $\left(T_{\text {mean }}\right)$, precipitation $(P)$, reference evapotranspiration $\left(\mathrm{ET}_{0}\right)$, and weather water balance $\left(P-\mathrm{ET}_{0}\right)$ at the different phenological stages and from budbreak to harvest (total). Data are from the meteorological station of Els Hostalets de Pierola $\left(4 I^{\circ} 3 I^{\prime} 59^{\prime \prime} \mathrm{N}, I^{\circ} 48^{\prime} 3 I^{\prime \prime} \mathrm{W}\right)$

\begin{tabular}{|c|c|c|c|c|}
\hline Period & $T_{\text {mean }}$ & $P$ & $\mathrm{ET}_{0}$ & $P-\mathrm{ET}_{\mathrm{O}}$ \\
\hline & ${ }^{\circ} \mathrm{C}$ & 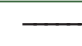 & $\mathrm{mm}$ & 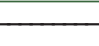 \\
\hline \multicolumn{5}{|l|}{2009} \\
\hline Dormancy & 7.5 & 249.1 & 111.9 & 137.3 \\
\hline Vegetative growth & 13.6 & 176.2 & 274.1 & -73.5 \\
\hline Berry growth & 22.2 & 82.7 & 186.3 & -142.9 \\
\hline Ripening & 24.1 & 33.9 & 142.2 & -88.7 \\
\hline Post-harvest & 19.9 & 145.7 & 213.7 & -72.7 \\
\hline Total & 17.5 & 687.6 & 928.2 & -240.6 \\
\hline \multicolumn{5}{|l|}{2011} \\
\hline Dormancy & 7.9 & 68.4 & 236.6 & -168.2 \\
\hline Vegetative growth & 14.5 & 303.2 & 306.7 & -3.5 \\
\hline Berry growth & 20.4 & 84.6 & $\mid 48.5$ & -63.9 \\
\hline Ripening & 22.1 & 35.1 & 185.1 & -150.0 \\
\hline Post-harvest & 20.9 & $|7| .3$ & 254.8 & -83.5 \\
\hline Total & 17.2 & 662.6 & 1031.8 & -369.2 \\
\hline
\end{tabular}

$2.3 \mathrm{~mm}$ diam. fiber-optic cable (model UNI410, PP Systems, Haverhill, MA). The lens was mounted on a tripod and held in a nadir orientation at $\sim 0.75 \mathrm{~m}$ above the canopy. The resulting measured area was about $15 \mathrm{~cm}$ in diameter. Three scans were collected at each vine and internally averaged.

Values of NDVI and WI were derived from apparent reflectance (i.e., radiance/irradiance) and calculated as follows:

$$
\begin{aligned}
& \mathrm{NDVI}=\left(R_{900}-R_{680}\right) /\left(R_{900}+R_{680}\right) \\
& \mathrm{WI}=R_{900} / R_{970}
\end{aligned}
$$

where $R$ indicates apparent reflectance and the subindices indicate the respective wavelengths in nanometers.

\section{Yield and Quality Parameters}

Harvest took place during the second and third weeks of August throughout the years of the study. Yield per vine was determined in the field. Afterward, berries were carried to the lab in coolers and pressed and filtered to obtain the must for quality parameters analysis. Total soluble solids (TSS, $\left.{ }^{\circ} \mathrm{Brix}\right)$ were determined using a refractometer (MASTER-M Refractometer, Atago Co., Ltd., Tokyo, Japan) and TA (g tartaric acid L ${ }^{-1}$ ) was determined by titration with $0.1 \mathrm{M} \mathrm{NaOH}$. Maturity index (IMAD) was calculated as the ratio between TSS and TA. It is worth noting that the berries were intended for cava production and were therefore considered at optimum ripening, in other words, harvested, at TSS $\sim 18\left({ }^{\circ}\right.$ Brix $)$ and TA $\sim 10\left(\mathrm{~g}\right.$ tartaric acid $\left.\mathrm{L}^{-1}\right)$.

\section{Statistical Analyses}

Data were analyzed using the statistical package SPSS 19.0 (SPSS Inc., Chicago IL). Correlation and regression analyses were used to study the relationships among vine canopy and water status parameters, yield and quality attributes, and spectral indices. Significant differences in the parameters studied were determined by ANOVA by considering vineyard and year as sources of variation. Means were compared using the Bonferroni test.

\section{RESULTS \\ Weather Conditions}

Mean temperatures were close to the long-term average (i.e., mean annual temperature $15^{\circ} \mathrm{C}$ ) throughout the years of the study but cumulative precipitation was above the mean annual rainfall (i.e., $530 \mathrm{~mm}$ ) (Table 1). In the years of study, according to the weather water balance, there was ample water availability over the vegetative growth period (March and April). Water deficits had a larger incidence during the phase of initial berry growth in 2009 $\left(P-\mathrm{ET}_{0}=-143 \mathrm{~mm}\right)$, whereas in 2011 they had a larger incidence from veraison to harvest $\left(P-\mathrm{ET}_{0}=-150 \mathrm{~mm}\right)$ (Table 1).

\section{Vine Vigor and Water Status at Veraison}

There were significant differences in fIPAR between years. Average fIPAR was $69.8 \pm 2.0 \%(\mathrm{avg} \pm$ SEM $)$ and $66.2 \pm 1.3 \%$ in 2009 and 2011, respectively. In addition, fIPAR showed significant differences among vineyards $(P<0.01)$ ranging from $56.4 \pm 2.7 \%$ to $78.7 \pm 2.4 \%$ in 2009 whereas, in 2011 , fIPAR ranged from $61.4 \pm 2.36 \%$ to $71.9 \pm 4.80 \%$ among vineyards (Table 2).

Predawn water potential showed significant differences between years $(P<0.01)$ (Table 2$)$. Average $\Psi_{\mathrm{p}}$ values were $-0.39 \pm 0.02 \mathrm{MPa}(\operatorname{avg} \pm \mathrm{SEM})$ and $-0.27 \pm 0.02 \mathrm{MPa}$, in 2009 and 2011 , respectively. In addition, $\Psi_{\mathrm{p}}$ varied significantly $(P<0.01)$ among vineyards in 2009 , with a minimum value of $-0.46 \pm 0.04 \mathrm{MPa}$ and a maximum of $-0.27 \pm 0.04 \mathrm{MPa}$. Contrastingly, there were no significant differences in $\Psi_{\mathrm{p}}$ among vineyards in 2011, with $\Psi_{\mathrm{p}}$ ranging from $-0.42 \pm 0.11 \mathrm{MPa}$ to $-0.19 \pm 0.01 \mathrm{MPa}$ among vineyards.

Values of $\Delta T_{\mathrm{m}}$ were significantly different $(P<0.01)$ between years and among vineyards within a year. Average $\Delta T_{\mathrm{m}}$ in 2009 was $-4.79 \pm 0.39^{\circ} \mathrm{C}$, ranging from $-6.72 \pm 0.18^{\circ} \mathrm{C}$ to $-3.05 \pm$ $0.19^{\circ} \mathrm{C}$ among vineyards. Average $\Delta T_{\mathrm{m}}$ in 2011 was $-2.29 \pm$ $0.30^{\circ} \mathrm{C}$, ranging from $-3.67 \pm 0.00^{\circ} \mathrm{C}$ to $-0.38 \pm 0.37^{\circ} \mathrm{C}$ among vineyards (Table 2).

No significant relationships $(P>0.05)$ emerged between water status parameters (i.e., $\Psi_{\mathrm{p}}$ and $\Delta T_{\mathrm{m}}$ ) and fIPAR, except in 2011, when lower fIPAR was marginally related to higher $\Psi_{\mathrm{p}}\left(r^{2}=\right.$ $0.50, P<0.10)$.

Table 2. Vineyard average ( \pm standard error of the mean), minimum and maximum values of predawn water potential ( $\left.\Psi_{\mathrm{p}}\right)$, leaf to air temperature difference at midday $\left(\Delta T_{m}\right)$ and intercepted fractional PAR (fIPAR). Values at each vineyard are the mean of three measurements obtained at veraison

\begin{tabular}{|c|c|c|c|c|c|c|}
\hline \multirow[b]{2}{*}{ Statistics } & \multicolumn{2}{|c|}{$\Psi_{\mathrm{P}}$} & \multicolumn{2}{|c|}{$\Delta T_{\mathrm{m}}$} & \multicolumn{2}{|c|}{ fIPAR } \\
\hline & 2009 & 2011 & 2009 & 2011 & 2009 & 2011 \\
\hline & \multicolumn{2}{|c|}{$\mathrm{MPa}$} & \multicolumn{2}{|c|}{${ }^{\circ} \mathrm{C}$} & 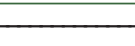 & +2 \\
\hline Mean & $-0.39 \pm 0.02 * *$ & $-0.27 \pm 0.02$ & $-4.79 \pm 0.39 * *$ & $-2.29 \pm 0.30$ & $70 \pm 2.0 * *$ & $66 \pm 1.3$ \\
\hline Minimum & $-0.46 \pm 0.04$ & $-0.42 \pm 0.11$ & $-6.72 \pm 0.18$ & $-3.67 \pm 0.00$ & $56 \pm 2.7$ & $61 \pm 2.4$ \\
\hline Maximum & $-0.27 \pm 0.04$ & $-0.19 \pm 0.01$ & $-3.05 \pm 0.19$ & $-0.38 \pm 0.37$ & $79 \pm 2.4$ & $72 \pm 4.8$ \\
\hline
\end{tabular}
in 2009 and 2011 .

** Significant differences between years at the 0.01 probability level. 
Table 3. Vineyard average ( \pm standard error of the mean), minimum and maximum values of yield, berry weight (BW), total soluble solids (TSS), titratable acidity (TA) and maturity index (IMAD). Values at each vineyard are the mean of three measurements obtained at harvest in 2009 and $20 \mathrm{II}$.

\begin{tabular}{|c|c|c|c|c|c|c|c|c|c|c|}
\hline \multirow[b]{2}{*}{ Statistics } & \multicolumn{2}{|c|}{ Yield } & \multicolumn{2}{|c|}{ BW } & \multicolumn{2}{|c|}{ TSS } & \multicolumn{2}{|c|}{ TA } & \multicolumn{2}{|c|}{ IMAD } \\
\hline & 2009 & 2011 & 2009 & 2011 & 2009 & 2011 & 2009 & 2011 & 2009 & 2011 \\
\hline & $-k \varepsilon$ & 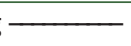 & 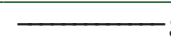 & $g$ & ${ }^{\circ} \mathrm{Br}$ & $x-$ & - g tartar & acid $L^{-1}-$ & & \\
\hline Mean & $5.3 \pm 0.4 I^{* *}$ & $6.2 \pm 0.36$ & $170.7 \pm 4.93$ & $\mid 58.5 \pm 6.31$ & $19.0 \pm 0.60^{* *}$ & $18.8 \pm 0.32$ & $10.9 \pm 0.39$ & $10.9 \pm 0.36$ & $1.78 \pm 0.11$ & $1.77 \pm 0.08$ \\
\hline Minimum & $4.1 \pm 0.52$ & $4.6 \pm 1.16$ & $166.0 \pm 36.70$ & $137.0 \pm 35.36$ & $15.8 \pm 0.92$ & $17.3 \pm 0.64$ & $9.0 \pm 1.01$ & $9.1 \pm 0.36$ & $1.57 \pm 0.28$ & $1.40 \pm 0.19$ \\
\hline Maximum & $7.1 \pm 0.29$ & $7.9 \pm 1.68$ & $178.7 \pm 10.42$ & $180.0 \pm 19.80$ & $21.0 \pm 0.07$ & $19.9 \pm 0.40$ & $12.5 \pm 0.46$ & $12.7 \pm 0.72$ & $2.34 \pm 0.09$ & $2.20 \pm 0.24$ \\
\hline
\end{tabular}

** Significant differences between years at the 0.01 probability level.

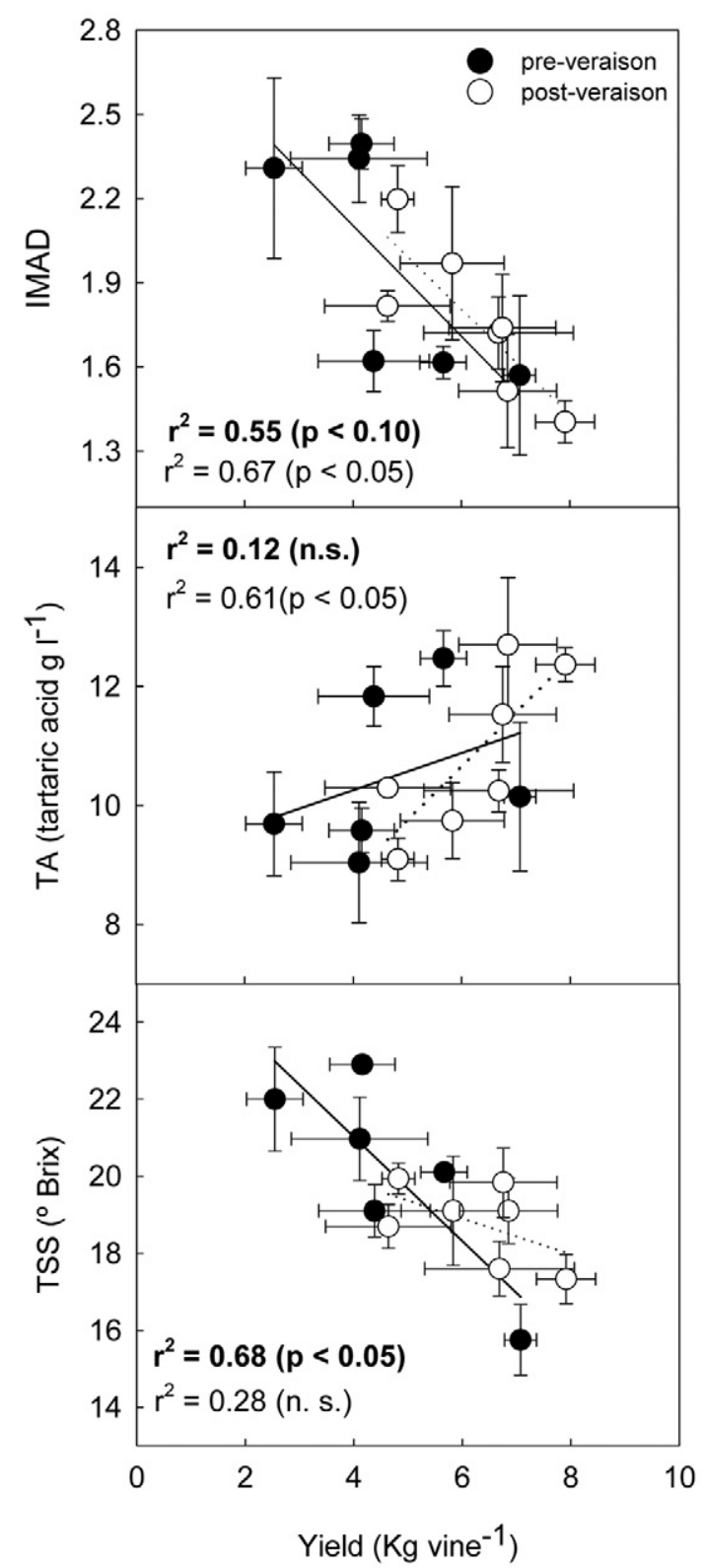

Fig. I. Relationship between berry yield and quality parameters (total soluble solids, TSS; titratable acidity, TA; and maturity index, IMAD) in Chardonnay vineyards. Each value corresponds to the average of three measurements in each vineyard ( $n=6$ and $n=7$ for pre- and postveraison, respectively). Coefficients of determination (and significance) under pre- and post-veraison water deficits are indicated in bold and normal characters, respectively.

\section{Fruit Yield and Quality Attributes}

There were significant differences in yield and TSS between years $(P<0.01)$, whereas TA and IMAD did not differ between years. Yield was significantly higher in 2011 than in 2009 (average values), whereas TSS was significantly lower in 2009 than in 2011 (Table 3).

Yield varied significantly among vineyards within a year $(P<$ $0.05)$. In 2009, yield ranged from $4.1 \pm 0.52 \mathrm{~kg} \mathrm{vine}^{-1}$ to $7.1 \pm$ $0.29 \mathrm{~kg} \mathrm{vine}^{-1}$ (avg \pm SEM) among vineyards, whereas in 2011, minimum and maximum yield were $4.6 \pm 1.16 \mathrm{~kg} \mathrm{vine}^{-1}$ and $7.9 \pm$ $1.68 \mathrm{~kg} \mathrm{vine}^{-1}$, respectively. The TSS showed significant differences among vineyards in $2009(P<0.01)$, but no significant differences emerged in 2011. In 2009, TSS values ranged from $15.8 \pm$ $0.92^{\circ}$ Brix to $21.0 \pm 0.07^{\circ}$ Brix among vineyards, whereas in 2011, TSS values ranged from $17.3 \pm 0.64^{\circ} \mathrm{Brix}$ to $19.9 \pm 0.40^{\circ} \mathrm{Brix}$. In addition, there were significant differences among vineyards in TA and IMAD in 2009 and 2011. Titratable acidity ranged from $9.0 \pm 1.01$ to $12.5 \pm 0.46 \mathrm{~g}$ tartaric acid $\mathrm{L}^{-1}$ in 2009 , whereas in 2011 , TA values ranged from $9.1 \pm 0.36 \mathrm{~g}$ tartaric acid $\mathrm{L}^{-1}$

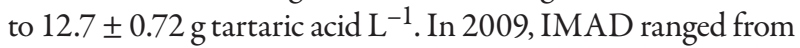
$1.57 \pm 0.28$ to $2.34 \pm 0.09$ among vineyards, whereas in 2011, IMAD ranged from $1.40 \pm 0.19$ to $2.20 \pm 0.24$ (Table 3).

In 2009, TSS was marginally related to yield $(r=-0.49, P<$ $0.10, n=7)$, whereas no significant relationship was observed between yield and either TA or IMAD. However, significant relationships emerged when a single data point (data not shown) corresponding to a vineyard harvested at non optimum ripeness (i.e., IMAD < 1.0) was disregarded. Thus, in 2009, increased yield was accompanied by a decrease in both TSS $(r=-0.82, P<$ $0.01, n=6)$ and $\operatorname{IMAD}(r=-0.74, P<0.05, n=6)$ (Fig. 1$)$, whereas no significant relationship emerged between yield and TA. Contrastingly, in 2011, yield and TSS were not significantly related $(r=-0.54, P=0.22)$, whereas TA and IMAD were closely related to yield with $r=0.78(P<0.05)$ and $r=-0.83(P<$ $0.01)$ for TA and IMAD, respectively. As the regression models between yield and berry quality attributes (TSS and IMAD) did not show significant differences between years (ANCOVA analysis, $P>0.05)$, data from both years were pooled. Thus, across years, higher yield was associated with higher TA $(r=$ $0.55, P<0.05)$ as well as with lower TSS $(r=-0.76, P<0.01)$ and lower IMAD $(r=-0.79, P<0.01)$.

Berry weight (BW) did not show significant differences between years or among vineyards within a year. Average BW was $170.7 \pm 4.93 \mathrm{~g}(\mathrm{avg} \pm \mathrm{SEM})$ in 2009 and $158.5 \pm 6.31 \mathrm{~g}$ in 2011. In 2009 , BW ranged from $166.0 \pm 36.70 \mathrm{~g}$ to $178.7 \pm 10.42 \mathrm{~g}$ and, in 2011 , it ranged from $137.0 \pm 35.36 \mathrm{~g}$ to $180.0 \pm 19.80 \mathrm{~g}$. Yield was significantly related to $\mathrm{BW}$ in $2011(r=0.80, P<0.01)$, whereas no significant relationship emerged in 2009. In addition, must quality parameters were not related to changes in BW in the years of study (data not shown). 
Table 4. Correlation coefficients between berry yield and composition (total soluble solids [TSS], titratable acidity [TA], maturity index [IMAD]) and predawn water potential $\left(\Psi_{\mathrm{p}}\right)$, leaf to air temperature difference at midday $\left(\Delta T_{\mathrm{m}}\right)$ and intercepted fractional PAR (fIPAR) in Chardonnay vineyards for pre- and post- veraison water deficits ( $n=6$ and $n=7$, respectively). Significant correlations at the 0.05 and 0.01 probability levels are indicated in bold and italics, respectively.

\begin{tabular}{|c|c|c|c|c|c|c|c|c|}
\hline \multirow[b]{2}{*}{ Parameter } & \multicolumn{2}{|c|}{ Yield } & \multicolumn{2}{|c|}{ TSS } & \multicolumn{2}{|c|}{ TA } & \multicolumn{2}{|c|}{ IMAD (TSS/TA) } \\
\hline & Pre-veraison & Post-veraison & Pre-veraison & Post-veraison & Pre-veraison & Post-veraison & Pre-veraison & Post-veraison \\
\hline & $-\mathrm{kg}$ & $n e^{-1}$ & ${ }^{\circ} \mathrm{E}$ & $\mathrm{ix}$ & - $\mathrm{g}$ tartar & acid $L^{-I}$ & & \\
\hline$\Psi_{\mathrm{pd}}, \mathrm{MPa}$ & -0.78 & -0.41 & 0.51 & 0.81 & -0.38 & -0.32 & 0.53 & 0.55 \\
\hline$\Delta T_{\mathrm{m}},{ }^{\circ} \mathrm{C}$ & -0.06 & -0.83 & -0.05 & 0.59 & -0.24 & -0.32 & 0.18 & 0.49 \\
\hline fIPAR, \% & 0.49 & 0.03 & -0.86 & -0.69 & 0.32 & -0.14 & -0.74 & -0.14 \\
\hline
\end{tabular}

\section{Dependence of Yield and Quality Attributes on Water Status and Vine Vigor}

In the years of study, yield was found to be related to vine vigor and vine water status to a variable extent. Thus, in 2009, yield decreased along with increasing $\Psi_{\mathrm{p}}$ at veraison $(r=-0.78$, $P<0.10, n=6)$, whereas yield was significantly related to $\Delta T_{\mathrm{m}}(r=$ $-0.83, P<0.05)$ in 2011 (Table 4).

Berry quality attributes were found to be related to vine water status and vigor to a varying degree depending on the year and quality parameter. There were no significant relationships between $\mathrm{BW}$ and fIPAR or water status parameters (i.e., $\Psi_{\mathrm{p}}$ and $\Delta T_{\mathrm{m}}$ ) in the years of study (data not shown). Total soluble solids were found to decrease along with increased fIPAR with $r=-0.86(P<0.05$, $n=6)$ and $r=-0.69(P<0.10)$ in 2009 and 2011 , respectively. In addition, in 2011, TSS was significantly related to $\Psi_{\mathrm{p}}$ with $r=0.81$ $(P<0.05)$ (Table 4). In the years of study, no significant relationships were found between TA and fIPAR or between TA and water status parameters. Finally, IMAD decreased along with increased $\operatorname{fIPAR}(r=-0.74, P<0.05, n=6)$ in 2009, whereas no significant relationship emerged between IMAD and FIPAR in 2011.

\section{Predicting Yield and Quality Attributes Using Hyperspectral Indices}

The NDVI showed significant differences $(P<0.01)$ between years, but no significant differences emerged among vineyards within a year. Average values of NDVI were $0.86 \pm 0.01$ (avg \pm SEM) and $0.82 \pm 0.01$ in 2009 and 2011, respectively. In 2009, NDVI ranged from $0.84 \pm 0.02$ to $0.88 \pm 0.01$, whereas in 2011, NDVI ranged from $0.81 \pm 0.01$ to $0.85 \pm 0.01$ among vineyards.

There were significant differences in WI between years $(P<$ $0.01)$ and among vineyards within a year $(P<0.05)$. Average WI in 2009 was $1.104 \pm 0.01$, ranging from $1.078 \pm 0.01$ to $1.121 \pm$ 0.01 among vineyards. Average WI in 2011 was $1.122 \pm 0.01$, ranging from $1.077 \pm 0.01$ to $1.151 \pm 0.01$ among vineyards.

In 2009, NDVI was marginally related to yield with $r=0.79$ $(P<0.10)$, whereas this correlation was not significant in 2011 (Fig. 2). Additionally, in 2009, NDVI was significantly related to TSS $(r=-0.90, P<0.01, n=6)$ and $\operatorname{IMAD}(r=-0.95, P<0.01, n=6)$ (Fig. 3), whereas in 2011, NDVI did not show significant relationships to berry quality attributes (i.e., TSS, ATT, and IMAD) (Fig. 3). Contrastingly, in 2011, WI was found to be related to quality attributes to a varying extent, whereas no significant relationships emerged in 2009. Thus, in 2011, WI was related to both TA $(r=$ $0.79, P<0.05)$ and $\operatorname{IMAD}(r=-0.82, P<0.05)$ (Fig. 3 ).

\section{DISCUSSION}

Predawn water potentials at veraison were higher than those obtained in field studies performed under rainfed conditions in Mediterranean environments (Koundouras et al., 2006; Serrano et al., 2010) and similar to those reported in field studies conducted under deficit irrigation programs (Grant et al., 2007; Patakas et al., 2005). The values of $\Psi_{\mathrm{p}}$ indicate that water stress was mild to moderate in the years of study (Carbonneau, 1998; Cifré et al., 2005). Consistent with the greater incidence of water deficits from budburst to veraison, $\Psi_{\mathrm{p}}$ at veraison was lower in 2009 than in 2011, when water deficits mainly occurred from veraison to harvest. Moreover, differences in water availability- driven by differences in soil water-holding capacity among vineyards-resulted in significant differences in $\Psi_{\mathrm{p}}$ at veraison in 2009, whereas in 2011, ample water availability from budburst to veraison resulted in no significant variation in $\Psi_{\mathrm{p}}$ among vineyards at veraison. Despite water deficits being mild to moderate, significant differences in yield between years-and among vineyards within a year-were recorded, with higher yield in 2011 (when $\Psi_{\mathrm{p}}$ indicated mild water stress) than in 2009 (when water stress was moderate). Thus, in agreement with previous studies, yield decreased along with increasing water deficits (Chaves et al., 2010; Koundouras et al., 2006; Medrano et al., 2003). The effects of vine vigor on yield have long been documented (Schultz and Matthews, 1988) and measures of leaf area and intercepted light have been related to berry yield (Pellegrino et al., 2005; Serrano et al., 2010). Similarly, remote estimates of vine vigor through PCD or NDVI have provided yield estimates in vineyards grown under both irrigated conditions (Lamb et al., 2008; Hall et al., 2002, 2011) and rainfed conditions (AcevedoOpazo et al., 2008). In accordance with the dependence of yield on

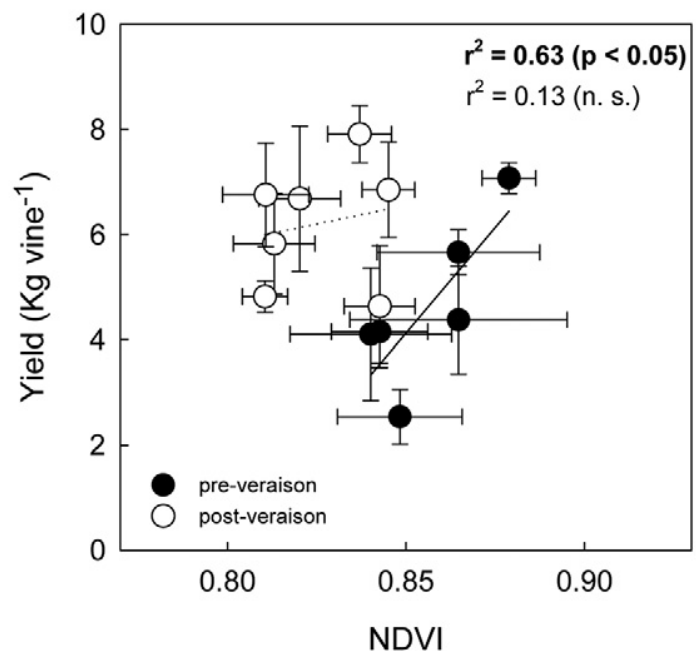

Fig. 2. Relationship between the normalized difference vegetation index (NDVI) and berry yield in Chardonnay vineyards. Each value corresponds to the average of three measurements in each vineyard ( $n=6$ and $n=7$ for pre- and post-veraison, respectively). Coefficients of determination (and significance) under pre- and post-veraison water deficits are indicated in bold and normal characters, respectively. 
fIPAR observed in our study, when water deficits occurred early in the growth cycle, NDVI was found to be related to yield (although marginally), whereas this relationship was not significant when water deficits occurred post-veraison. Similar results were reported in a study conducted in rainfed vineyards experiencing moderate to severe water deficits (Serrano et al., 2012).

Water deficits decrease yield through their influence on both leaf area (i.e., intercepted light) (Pellegrino et al., 2005) and stomatal conductance (Flexas et al., 2002), thus limiting C assimilation (Pérez Peña and Tarara, 2004) and changing the source-sink balance (Van Leeuwen et al., 2009). Because NDVI relates to the amount of photosynthetically active radiation absorbed by the canopy (Gamon et al., 1995; Serrano et al., 2000; Hall et al., 2002), our results suggest that variation in photosynthetically active biomass was a key determinant of yield under pre-veraison water deficits. Contrastingly, under post-veraison water deficits, yield was found to decrease along with increasing water deficits $\left(\Delta T_{\mathrm{m}}\right.$ at veraison accounted for $\sim 69 \%$ of variation in yield). Since the leaf to air temperature difference (i.e., $\Delta T_{\mathrm{m}}$ ) relates to stomatal aperture (Jones et al., 2002), our results suggest that changes in photosynthetic rate associated with variation in stomatal aperture (Flexas et al., 2002) largely influenced yield under post-veraison water deficits. In summary, our results show that variation in yield was mainly associated with changes in photosynthetic capacity (i.e., leaf biomass and leaf chlorophyll content) (Matthews and Anderson, 1988) under pre-veraison water deficits, whereas under post-veraison water deficits, when differences in light interception were minor, stomatal aperture largely determined variation in yield (Pérez Peña and Tarara, 2004). Consequently, NDVI was related to berry yield when water deficits had a large incidence at

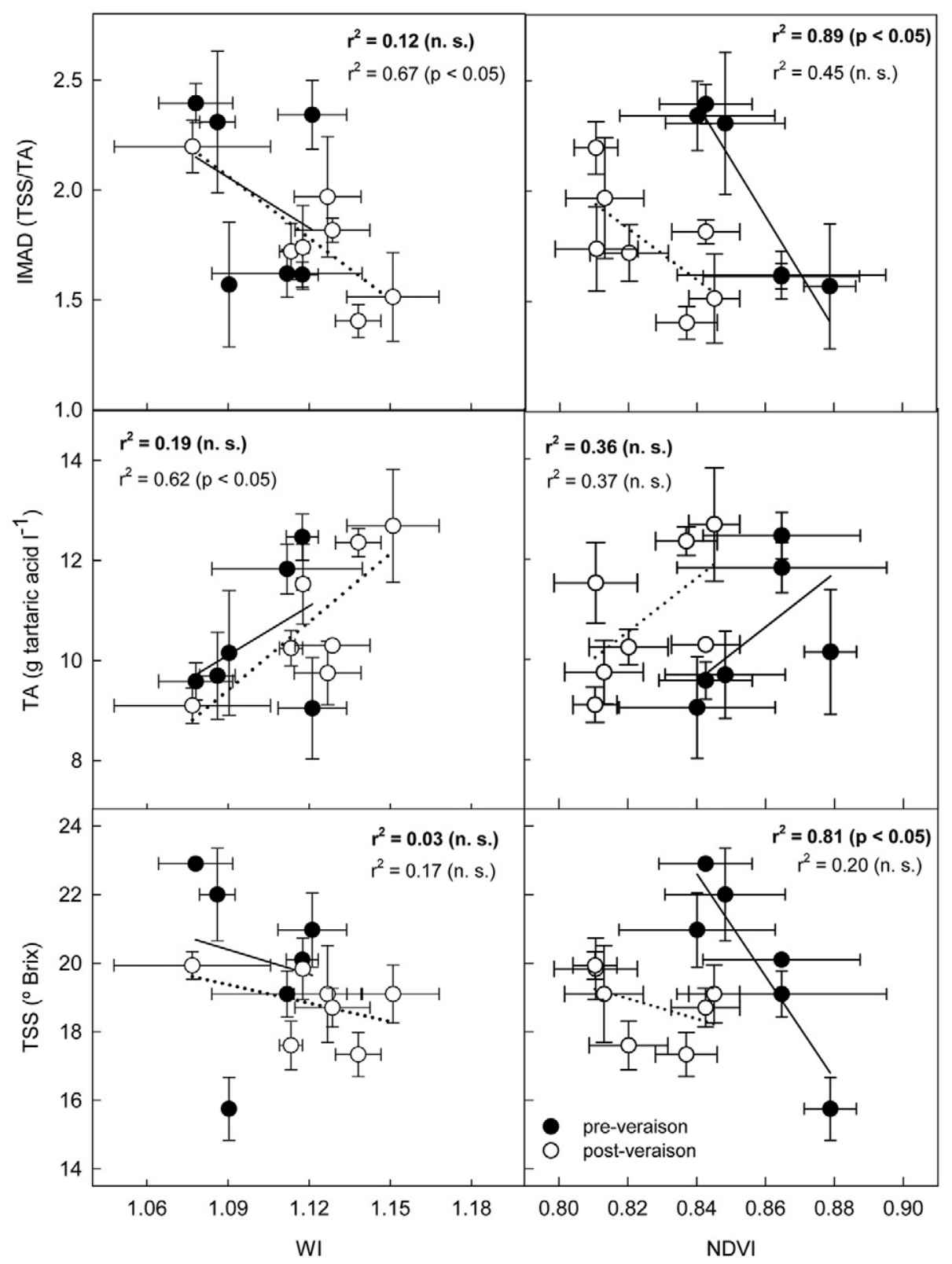

Fig. 3. Relationship between the spectral indices normalized difference vegetation index (NDVI) and water index (WI) and berry quality parameters (total soluble solids, TSS; titratable acidity, TA; and maturity index, IMAD) in Chardonnay vineyards. Each value corresponds to the average of three measurements in each vineyard ( $n=6$ and $n=7$ for pre- and post-veraison, respectively). Coefficients of determination (and significance) under preand post-veraison water deficits are indicated in bold and normal characters, respectively. 
pre-veraison, which is consistent with the widely known effects of early water deficits (i.e., before onset of veraison) on vegetative growth (Matthews et al., 1987). Contrastingly, NDVI was not related to yield when water deficits had a larger incidence postveraison, in agreement with previous studies (Acevedo-Opazo et al., 2008; Serrano et al., 2012). Hall et al. (2011) showed that the strength and direction of the correlation between NDVI and yield might vary at different phenological stages. In the present study, lack of correlation between NDVI and yield under post-veraison water deficits might be partly ascribed to the lack of dependence of yield on changes in photosynthetically active biomass, as mentioned above. In addition, it might be that NDVI acquired at veraison did not adequately capture the effects of post-veraison water deficits on yield. Therefore, in these rainfed vineyards, the timing of spectral data acquisition might also be critical in determining the capability of spectral indices at predicting berry yield.

Previous studies have shown the capability of WI to track variation in stomatal aperture in citrus trees (Dzikiti et al., 2010) and grapevines (Serrano et al., 2010). In addition, previous results have shown the aptitude of WI at characterizing variation in yield in vineyards experiencing moderate to severe water deficits, particularly post-veraison (Serrano et al., 2012). Contrastingly, in the present study, despite the close dependence of yield on vine water status observed under post-veraison water deficits, WI failed to provide estimates of yield. The ability of WI to estimate yield has been ascribed to the scaling of this index to leaf area (Serrano et al., 2000; Sims and Gamon, 2003) and to the capability of WI to track variation in stomatal aperture, as mentioned above. Therefore, it appears that minor variation in vine vigor, combined with the mild incidence of water deficits, probably prevented a successful estimate of yield using WI. More studies are needed to confirm this hypothesis.

In our study, increases in yield were associated with decreases in berry quality (i.e., low sugar content and high acidity) regardless of the timing of water deficits, as has been previously reported (Chaves et al., 2010; Medrano et al., 2003; Jackson and Lombard, 1993; Serrano et al., 2012). However, within each year, the relationships between berry quality attributes and yield were found to be variable: under pre-veraison water deficits, higher yield was associated with lower TSS, whereas higher yield was associated with higher TA under post-veraison water deficits. This variable dependence might be attributed to differences in weather conditions (particularly temperatures) as well as to differences in the timing of water deficits between years (Jackson and Lombard, 1993; Chaves et al., 2010). Jointly, these effects led to a lower sugar/acid balance (i.e., IMAD values) at harvest along with increasing yield.

Vine vigor also has a considerable effect on berry composition (Smart et al., 1982) and remote measurements of canopy vigor have provided reliable estimates of berry quality (Hall et al., 2011; Johnson et al., 2001; Lamb et al., 2008). In the present study, consistent with the dependence of TSS on yield observed under pre-veraison water deficits and the association between yield and vine vigor, NDVI was found to be related to TSS $\left(r^{2}=0.81\right)$ and IMAD $\left(r^{2}\right.$ $=0.89$ ), whereas no significant relationship emerged when water deficits occurred post-veraison. These results are in agreement with previous studies conducted in irrigated vineyards experiencing mild to moderate water deficits where vegetation indices derived from reflectance imagery in the red and near infrared bands (e.g., NDVI or PCD) were used to estimate differences in fruit quality
(Hall et al., 2002; Johnson et al., 2001). Under post-veraison water deficits, consistent with the observed dependence of TA on yield, and the association between yield and vine water status (i.e., $\Delta T_{\mathrm{m}}$ ), WI was found to be significantly related to TA $\left(r^{2}=0.62\right)$ and IMAD $\left(r^{2}=0.67\right)$. Therefore, in agreement with previous results obtained in vineyards experiencing moderate to severe water stress (Serrano et al., 2012), WI provided consistent estimates of TA and IMAD. More studies are needed, with particular emphasis on the timing of data acquisition with respect to the period of incidence of water deficits, to further explore the usefulness of narrow-band spectral indices of canopy structure and water status at estimating berry quality attributes. In addition, because the relationships between the spectral indices NDVI and WI and berry yield and composition found in our study were derived from a small number of observations, further work is needed to validate the predictive capability of NDVI and WI at estimating berry yield and composition and ensure the applicability of these spectral indices to management practices.

In summary, in rainfed vineyards the timing (and extent) of water deficits and their effects on both vine vigor and water status (i.e., stomatal conductance) might be critical in determining the capability of the spectral indices to assess berry yield and composition. In addition, the timing of spectral data acquisition with respect to the timing of water deficits might be an important determinant of the spectral indices' capability to estimate berry yield and composition in rainfed vineyards. Our results might have potential applications in precision viticulture activities such as selective harvesting according to grape quality attributes and the assessment of ripening.

\section{CONCLUSIONS}

In the present study, characterized by mild to moderate water deficits, vine vigor and water status influenced berry yield and quality attributes differently depending on when water deficits occurred. With the pre-veraison water deficits, yield and vine vigor (i.e., fIPAR) were weakly related. With the post-veraison water deficits, yield and vine water status (i.e., $\Delta T_{\mathrm{m}}$ ) were significantly related. Consistent with the observations described above, and due to the close association between yield and berry composition, NDVI measurements were related to yield and sugar content under pre-veraison water deficits. In contrast, despite the close association between yield and vine water status with the postveraison water deficits, the relationship between WI and yield was not significant. Nonetheless, WI explained a large percentage of variation in berry titratable acidity under post-veraison water deficits. In addition, NDVI was related to the maturity index (IMAD) with the pre-veraison water deficits, whereas WI was related to IMAD with the post-veraison water deficits. Results showed that, in rainfed vineyards, the suitability of spectral indices for estimating yield and berry quality attributes is subject to the timing of water deficits. Additional studies are needed to further explore the predictive capability of the spectral indices NDVI and WI for estimating berry yield and composition.

\section{ACKNOWLEDGMENTS}

This study was carried out with the financial support of grant 9-INCREC-09 (UPC) and grant AGL2009-13105-C03-03 (Ministerio de Ciencia e Innovación, Spain). 


\section{REFERENCES}

Acevedo-Opazo, C., B. Tisseyre, S. Guillaume, and H. Ojeda. 2008. The potential of high spatial resolution information to define within-vineyard zones related to vine water status. Precis. Agric. 9:285-302. doi:10.1007/ s11119-008-9073-1

Bravdo, B., Y. Hepner, C. Loinger, S. Cohen, and H. Tabacman. 1985. Effect of irrigation and crop level on growth, yield and wine quality of Cabernet Sauvignon. Am. J. Enol. Vitic. 36:132-139.

Carbonneau, A. 1998. Irrigation, vignoble et produit de la vigne. In: J.R. Tiercelin, editor, Traité d'irrigation. Chapitre IV. Aspects Qualitatifs. Lavoisier Tec and Doc, Paris. p. 257-298.

Chaves, M.M., O. Zarrouk, R. Francisco, J.M. Costa, T. Santos, A.P. Regalado et al. 2010. Grapevine under deficit irrigation: Hints from physiological and molecular data. Ann. Bot. (Lond.) 105:661-676. doi:10.1093/aob/mcq030

Choné, X., C. Van Leeuwen, P. Chery, and P. Ribereau-Gayon. 2001. Terroir influence on water status and nitrogen status of non irrigated Cabernet Sauvignon (Vitis vinifera): Vegetative development, must and wine composition. South African J. Enol. Vitic. 22:8-15.

Cifré, J., J. Bota, J. Escalona, H. Medrano, and J. Flexas. 2005. Physiological tools for irrigation scheduling in grapevine (Vitis vinifera $\mathrm{L}$.): An open gate to improve water-use efficiency? Agric. Ecosyst. Environ. 106:159-170. doi:10.1016/j.agee.2004.10.005

Coombe, B.G. 1989. The grape berry as a sink. Acta Hortic. 239:149-158.

Deloire, A., A. Carbonneau, P. Wang, and H. Ojeda. 2004. Vine and water a short review. J. Int. Sci. Vigne Vin 38:1-13.

Dzikiti, S., J.S. Verreynne, J. Stuckens, A. Strever, W.W. Verstraeten, R. Swennen, and P. Coppin. 2010. Determining the water status of Satsuma mandarin trees [Citrus Unshiu Marcovitch] using spectral indices and by combining hyperspectral and physiological data. Agric. For. Meteorol. 150:369-379. doi:10.1016/j.agrformet.2009.12.005

Dobrowski, S.Z., J.C. Pushnik, P.J. Zarco-Tejada, and S.L. Ustin. 2005. Simple reflectance indices track heat and water stress-induced changes in steadystate chlorophyll fluorescence at the canopy scale. Remote Sens. Environ. 97:403-414. doi:10.1016/j.rse.2005.05.006

Flexas, J., J. Bota, J.M. Escalona, B. Sampol, and H. Medrano. 2002. Effects of drought on photosynthesis in grapevines under field conditions: An evaluation of stomatal and mesophyll limitations. Funct. Plant Biol. 29:461-471. doi:10.1071/PP01119

Flexas, J., J. Briantais, Z. Cerovic, H. Medrano, and I. Moya. 2000. Steadystate and maximum chlorophyll fluorescence responses to water stress in grapevine leaves: A new remote sensing system. Remote Sens. Environ. 73:283-297. doi:10.1016/S0034-4257(00)00104-8

Gamon, J.A., C. Field, M. Goulden, K. Griffin, A. Hartley, G. Joel, J. Peñuelas, and R. Valentini. 1995. Relationships between NDVI, canopy structure, and photosynthesis in three Californian vegetation types. Ecol. Appl. 5:28-41. doi:10.2307/1942049

Grant, O., L. Tronina, H. Jones, and M. Chaves. 2007. Exploring thermal imaging variables for the detection of stress responses in grapevine under different irrigation regimes. J. Exp. Bot. 58:815-825. doi:10.1093/jxb/erl153

Hall, A., D. Lamb, B. Holzapfel, and J. Louis. 2002. Optical remote sensing application in viticulture. A review. Aust. J. Grape Wine Res. 8:36-47. doi:10.1111/j.1755-0238.2002.tb00209.x

Hall, A., D. Lamb, B. Holzapfel, and J. Louis. 2011. Within-season temporal variation in correlations between vineyard canopy and winegrape composition and yield. Precis. Agric. 12:103-117. doi:10.1007/s11119-010-9159-4

Jackson, D.I., and P.B. Lombard. 1993. Environmental and management practices affecting berry composition and wine quality-A review. Am. J. Enol. Vitic. 44:409-430.

Johnson, J.F., D. Bosch, D. Williams, and B. Lobitz. 2001. Remote sensing of vineyard management zones: Implications for wine quality. Appl. Eng. Agric. 17:557-560. doi:10.13031/2013.6454

Jones, H., M. Stoll, T. Santos, C. Sousa, M. Chaves, and O. Grant. 2002. Use of infrared thermography for monitoring stomatal closure in the field: Application to grapevine. J. Exp. Bot. 53:2249-2260. doi:10.1093/jxb/erf083

Koundouras, S., V. Marinos, A. Gkoulioti, Y. Kotseridis, and C. Van Leeuwen. 2006. Influence of vineyard location and vine water status on fruit maturation of nonirrigated cv. Agiorgitiko (Vitis vinifera L.). Effects on wine phenolic and aroma components. J. Agric. Food Chem. 54:5077-5086. doi:10.1021/jf0605446
Koundouras, S., C. van Leeuwen, G. Seguin, and Y. Glories. 1999. Influence of water status on vine vegetative growth, berry ripening and wine characteristics in Mediterranean zone (example of Nemea, Greece, variety SaintGeorges, 1997). J. Int. Sci. Vigne Vin 33:149-160.

Lamb, D. 2000. The use of qualitative airborne multispectral imaging for managing agricultural crops- a case study in south-eastern Australia. Aust. J. Exp. Agric. 40:725-738. doi:10.1071/EA99086

Lamb, D., M. Weedon, and R. Bramley. 2008. Using remote sensing to predict grape phenolics and colour at harvest in a Cabernet Sauvignon vineyard: Timing observations against vine phenology and optimising image resolution. Aust. J. Grape Wine Res. 10:46-54. doi:10.1111/j.1755-0238.2004. tb00007.x

Matthews, M.A., and M. Anderson. 1988. Fruit ripening in Vitis-vinifera L.Responses to seasonal water deficits. Am. J. Enol. Vitic. 39:313-320.

Matthews, M.A., M. Anderson, and H. Schultz. 1987. Phenologic and growthresponses to early and late season water deficits in Cabernet franc. Vitis 26:147-160.

Medrano, H., J.M. Escalona, J. Cifré, J. Bota, and J. Flexas. 2003. A ten-year study on the physiology of two Spanish grapevine cultivars under field conditions: Effects of water availability from leaf photosynthesis to grape yield and quality. Funct. Plant Biol. 30:607-619. doi:10.1071/FP02110

Ojeda, H., A. Deloire, and A. Carbonneau. 2001. Influence of water deficits on grape berry growth. Vitis 40:141-145.

Patakas, A., B. Noitsakis, and A. Chouzouri. 2005. Optimization of irrigation water use in grapevines using the relationship between transpiration and plant water status. Agric. Ecosyst. Environ. 106:253-259. doi:10.1016/j. agee.2004.10.013

Pellegrino, A., E. Lebon, T. Simonneau, and J. Wery. 2005. Towards a simple indicator of water stress in grapevine (Vitis vinifera L.) based on the differential sensitivities of vegetative growth components. Aust. J. Grape Wine Res. 11:306-315. doi:10.1111/j.1755-0238.2005.tb00030.x

Peñuelas, J., I. Filella, C. Biel, L. Serrano, and R. Savé. 1993. The reflectance at the $950-970 \mathrm{~nm}$ region as an indicator of plant water status. Int. J. Remote Sens. 14:1887-1905. doi:10.1080/01431169308954010

Pérez Peña, J.E., and J. Tarara. 2004. A portable whole canopy gas exchange system for several mature field-grown grapevines. Vitis 43:7-14.

Rodríguez-Pérez, J., D. Riaño, E. Carlisle, S. Ustin, and D. Smart. 2007. Evaluation of hyperspectral reflectance indexes to detect grapevine water status in vineyards. Am. J. Enol. Vitic. 58:302-317.

Schultz, H., and M.A. Matthews. 1988. Vegetative growth distribution during water deficits in Vitis-vinifera L. Aust. J. Plant Physiol. 15:641-656. doi:10.1071/PP9880641

Sepulcre-Cantó, G., P.J. Zarco-Tejada, J. Jiménez-Muñoz, J. Sobrino, M. Soriano, E. Fereres et al. 2007. Monitoring yield and fruit quality parameters in open-canopy tree crops under water stress. Implications for ASTER. Remote Sens. Environ. 107:455-470. doi:10.1016/j.rse.2006.09.014

Serrano, L., C. González-Flor, and G. Gorchs. 2010. Assessing vineyard water status using the reflectance based Water Index. Agric. Ecosyst. Environ. 139:490-499. doi:10.1016/j.agee.2010.09.007

Serrano, L., C. González-Flor, and G. Gorchs. 2012. Assessment of grape yield and composition using the reflectance based water index in Mediterranean rainfed vineyards. Remote Sens. Environ. 118:249-258. doi:10.1016/j. rse.2011.11.021

Serrano, L., S.L. Ustin, D.A. Roberts, J.A. Gamon, and J. Peñuelas. 2000. Deriving water content of chaparral vegetation from AVIRIS data. Remote Sens. Environ. 74:570-581. doi:10.1016/S0034-4257(00)00147-4

Sims, D., and J.A. Gamon. 2003. Estimation of vegetation water content and photosynthetic tissue area from spectral reflectance: A comparison of indices based on liquid water and chlorophyll absorption features. Remote Sens. Environ. 84:526-537. doi:10.1016/S0034-4257(02)00151-7

Smart, R., N. Shaulis, and E. Lemon. 1982. The effect of concord vineyard microclimate on yield. 1 . The effects of pruning, training, and shoot positioning on radiation microclimate. Am. J. Enol. Vitic. 33:99-108.

Van Leeuwen, C., O. Trégoat, X. Choné, B. Bois, D. Pernet, and J.P. Gaudillère. 2009. Vine water status is a key factor in grape ripening and vintage quality for red Bordeaux wine. How can it be assessed for vineyard management purposes? J. Int. Sci. Vigne Vin 43:121-134. 